\title{
Analgesic and Anti-Inflammatory Effects of Herbal Mixture Extracts in Mice
}

\author{
Mei-Yin Chien ${ }^{1,2}$, Cheng-Hung Chuang', Yi-Ting Lin1, Chih-Min Yang1, Chao-Hsiang Chen ${ }^{1,4^{*}}$ \\ ${ }^{1}$ Ko Da Pharmaceutical Co. Ltd., Taiwan \\ ${ }^{2}$ School of Dentistry, College of Oral Medicine, Taipei Medical University, Taiwan \\ ${ }^{3}$ Department of Nutrition, Master Program of Biomedical Nutrition, Hungkuang University, Taiwan \\ ${ }^{4}$ Graduate Institute of Pharmacognosy, Taipei Medical University, Taiwan \\ Email: *cmy@koda.com.tw
}

How to cite this paper: Chien, M.-Y., Chuang, C.-H., Lin, Y.-T., Yang, C.-M. and Chen, C.-H. (2018) Analgesic and Anti-Inflammatory Effects of Herbal Mixture Extracts in Mice. Pharmacology \& Pharmacy, 9, 1-9.

https://doi.org/10.4236/pp.2018.91001

Received: November 27, 2017

Accepted: January 7, 2018

Published: January 10, 2018

Copyright $\odot 2018$ by authors and Scientific Research Publishing Inc. This work is licensed under the Creative Commons Attribution International License (CC BY 4.0).

http://creativecommons.org/licenses/by/4.0/

\section{Open Access}

\begin{abstract}
Herbal mixture extracts (HME) comprised of Semen Sojae Nigrum, Fructus Cnidii, Radix Glycyrrhizae, and Cornu Cervi. Herein, we employed three mouse models, including hot-plate test, acetic acid (AA)-induced writhing test and AA-induced vascular permeability test, to determine analgesic and anti-inflammatory effects of HME. Results revealed that HME exhibited analgesic effects in hot-plate test and in AA-induced writhing test, as evidenced by increasing the latency to lick paws and decreasing AA-induced writhing counts, respectively. HME also significantly and dose-dependently decreased AA-induced vascular permeability, indicating HME exhibited anti-inflammatory effects. Similar improvement can be observed in aspirin treatment that used as positive control in this study. Most of medicinal effects of Fructus Cnidii are considered to attribute to coumarins, such as osthol (OST) and imperatorin (IMP) with several pharmacological activities. We then used OST and IMP as bioactive components in HME. The content of OST and IMP in HME was $3.57 \pm 0.10 \mathrm{mg} / \mathrm{g}$ and $1.20 \pm 0.02 \mathrm{mg} / \mathrm{g}$, respectively, from three independent batches. Only OST possessed inhibitory effects in three mouse models, suggesting that OST may partially involve in protective effects of HME. These results demonstrated that HME has a potential on anti-analgesic effects and anti-inflammatory actions.
\end{abstract}

\section{Keywords}

Analgesic Effects, Herbal Mixture Extracts, Inflammation, Mice

\section{Introduction}

Prevention and treatment of chronic diseases of herbal medicines may attribute 
to their synergistic actions [1]. The synergistic actions can be achieved by mediated either the same or different targets in a synergistic way as well as decreased the adverse effects or increased pharmacological activity by herbal-herbal interaction [2]. Herbal mixture extracts (HME) comprised of Semen Sojae Nigrum, Fructus Cnidii, Radix Glycyrrhizae, and Cornu Cervi. Semen Sojae Nigrum is the dried ripe seed of Glycine max (L.) Merr. with several pharmacological activities, including anti-osteoporosis [3], anti-inflammation [4], anti-cancer [5], anti-cardiovascular disease [6] and analgesic effects [7]. Fructus Cnidii is the dried ripe fruit of Cnidium monnieri (L.) Cuss. with some pharmacological effects, such as sedative effect [8], hypnotic action [8], anti-nociceptive effect [9], anti-cancer [10], and anti-inflammation [11]. Radix Glycyrrhizae is the dried root and rhizome of Glycyrrhiza uralensis Fisch., Glycyrrhiza inflata Bat. or Glycyrrhiza glabra L. with several biological functions, including anti-inflammation [12], anti-nociceptive activities [12], hepatoprotective effects [13], and anti-cancer [13]. Cornu Cervi is the ossified antler of Cervus elaphus Linnaeus or Cervus nippon Temminck with some traditional applications, such as anti-impotence, and relieving of blood stasis and swelling pain.

These specific functions of each herbal medicine led us to hypothesize that these components when used in combinations could serve as an effective prescription with analgesic effects and anti-inflammation. In the present study, we employed three mouse models, including hot-plate test, acetic acid (AA)-induced writhing test, and AA-induced peritoneal permeability test, to investigate the protective effects of HME. Most of medicinal effects of Fructus Cnidii are considered to attribute to coumarins, such as osthol (OST) and imperatorin (IMP) with several pharmacological activities. In addition, we used osthol (OST) and imperatorin (IMP) as bioactive components in HME. The content of OST and IMP was investigated by HPLC from three independent batches to ensure the quality of manufactured HME. The protective effects of OST and IMP in three mouse models were also determined.

\section{Materials and Methods}

\subsection{Preparation of HME}

The prescription of HME was developed by Ko Da Pharmaceutical Co. Ltd. (Taoyuan, Taiwan). Semen Sojae Nigrum, Fructus Cnidii, Radix Glycyrrhizae, and Cornu Cervi were purchased from Taiwan or China herbal markets and identified in the R\&D center of Ko Da Pharmaceutical Co. Ltd., where voucher specimens have been kept. $75 \mathrm{~kg}$ of Semen Sojae Nigrum and $25.2 \mathrm{~kg}$ of Fructus Cnidii were soaked in 10-fold (w/v) of 30\% (v/v) ethanol for $12 \mathrm{~h}$, and then extracted for $2 \mathrm{~h}$ followed by filtration through 40 -sieve mesh. $75 \mathrm{~kg}$ of Radix Glycyrrhizae were extracted in 12-fold (w/v) of $95 \%$ ethanol for $1 \mathrm{~h}$ followed by filtration through 40 -sieve mesh. All filtrates were collected and subjected to vacuum and reduced-pressure concentration to obtain $30 \mathrm{~kg}$ of extracts. $30 \mathrm{~kg}$ of Cornu Cervi were grinded to form powder and mixed with extracts at the ratio 
of $1: 1$ followed by dried in $60^{\circ} \mathrm{C}$ oven for $12 \mathrm{~h}$. The mixtures were granulated using granulator for $2 \mathrm{~h}$, and then passed through 40 -sieve mesh to obtain HME.

\subsection{Animals}

Male ICR mice (4-wk-old, 28 - $32 \mathrm{~g}$ ) were purchased from the National Laboratory Animal Center (Taipei, Taiwan). This study protocol was approved by the Institutional Animal Care and Use Committee of HungKuang University (approval No.: 10310). Mice were housed in cages with controlled temperature $\left(25^{\circ} \mathrm{C} \pm 2^{\circ} \mathrm{C}\right)$ and humidity $(65 \% \pm 5 \%)$ with $12 \mathrm{~h}$-light/dark cycles and were accommodated for $1 \mathrm{wk}$. During the accommodation and experimental periods, mice were supplied water ad libitum and a standard rodent diet (Lab 5001, Purina Mills) containing $59.8 \%$ carbohydrate, $23.4 \%$ protein, $4.5 \%$ crude fat, as indicated by the supplier.

\subsection{Hot-Plate Test}

Mice were randomly divided into nine groups ( $\mathrm{n}=6$ for each group) as follows: group 1, control; group 2, positive control; group 3, low dose of HME (77 $\mathrm{mg} / \mathrm{kg}$ ); group 4, medium dose of HME (154 mg/kg); group 5, high dose of HME (308 mg/kg); group 6, low dose of IMP $(0.6 \mathrm{mg} / \mathrm{kg})$; group 7, high dose of IMP $(1.2 \mathrm{mg} / \mathrm{kg})$; group 8 , low dose of OST $(2.2 \mathrm{mg} / \mathrm{kg})$; group 9 , high of OST $(4.4 \mathrm{mg} / \mathrm{kg})$. All groups, except positive control, were fed orally with normal saline or different doses of HME, IMP, and OST. Positive control mice were fed with aspirin $(250 \mathrm{mg} / \mathrm{kg})$ via i.p. injection. The temperature of the hot plate (Basile, Varese, Italy) was maintained at $55^{\circ} \mathrm{C} \pm 2{ }^{\circ} \mathrm{C}$. Mice were placed on hot plate and determined the latency to licking paws for the first time within $30 \mathrm{~s}$. The formula for calculating the difference of the latency to licking paws is the difference between before and after HME, OST, IMP or aspirin administration for $20 \mathrm{~min}$.

\subsection{AA-Induced Writhing Test}

Mice were randomly divided into nine groups ( $\mathrm{n}=5$ for each group) as follows: group 1, control; group 2, positive control; group 3, low dose of HME (77 $\mathrm{mg} / \mathrm{kg}$ ); group 4, medium dose of HME (154 mg/kg); group 5, high dose of HME (308 mg/kg); group 6, low dose of IMP $(0.6 \mathrm{mg} / \mathrm{kg})$; group 7, high dose of IMP $(1.2 \mathrm{mg} / \mathrm{kg})$; group 8 , low dose of OST $(2.2 \mathrm{mg} / \mathrm{kg})$; group 9 , high of OST $(4.4 \mathrm{mg} / \mathrm{kg})$. All groups were fed orally with normal saline, aspirin $(250 \mathrm{mg} / \mathrm{kg})$, or different doses of HME, IMP, and OST. After administration for $30 \mathrm{~min}$, mice were injected i.p. with $10 \mathrm{~mL} / \mathrm{kg}$ of $0.6 \%$ AA solution. The number of writhes produced in mice was counted within $10 \mathrm{~min}$.

\subsection{AA-Induced Vascular Permeability Test}

Mice were randomly divided into ten groups ( $\mathrm{n}=5$ for each group) as follows: group 1, control; group 2, AA; group 3, AA + positive control; group 4, AA + low dose of HME (77 mg/kg); group 5, AA + medium dose of HME (154 mg/kg); 
group 6, AA + high dose of HME (308 mg/kg); group 7, AA + low dose of IMP $(0.6 \mathrm{mg} / \mathrm{kg})$; group $8, \mathrm{AA}+$ high dose of IMP $(1.2 \mathrm{mg} / \mathrm{kg})$; group $9, \mathrm{AA}+$ low dose of OST (2.2 mg/kg); group 10, AA + high dose of OST (4.4 mg/kg). Mice were injected i.v. with $10 \mathrm{~mL} / \mathrm{kg}$ of $1 \%$ Evans Blue dye solution (Sigma-Aldrich, St. Louis MO, USA) followed by i.p. injection of $10 \mathrm{~mL} / \mathrm{kg}$ of $0.6 \%$ AA. Normal saline, aspirin $(250 \mathrm{mg} / \mathrm{kg})$, or different doses of HME, IMP, and OST were given orally $1 \mathrm{~h}$ prior to the injection of Evans Blue dye solution. Thirty minutes after injection of AA, mice were sacrificed by cervical dislocation. Peritoneal fluids were collected, and then washed with normal saline followed by centrifuged at $3000 \mathrm{rpm}$ for $10 \mathrm{~min}$. The supernatant was collected and determined the absorbance at $590 \mathrm{~nm}$ using a spectrophotometer (Perkin Elmer, Waltham, USA).

\subsection{Determination of OST and IMP Content in HME}

The test solution was prepared by mixing $1 \mathrm{~g}$ of HME with $50 \mathrm{~mL}$ of $70 \%(\mathrm{v} / \mathrm{v})$ methanol under shaking for $1 \mathrm{~h}$ on orbital shaker (Deagle, New Taipei City, Taiwan) followed by filtration through a $0.45 \mu \mathrm{m}$ filter. The standard solution was prepared by mixing OST and IMP (ChemFaces, Hubei, China) with methanol to obtain different concentrations through serial dilution. Analytical HPLC was performed on Hitachi D-7000 interface equipped with L-7100 pump, L-7420 UV detector and L-7200 autosampler (Tokyo, Japan). Chromatographic separation was carried out on a Mightysil RP-18 column $(250 \times 4.6 \mathrm{~mm}, 5 \mu \mathrm{m})$ using a gradient solvent system comprised of acetonitrile (A) and $0.1 \%(\mathrm{v} / \mathrm{v})$ acetic acid (B). Gradient profile was set as follows at 0 - 5 min with the ratio of $40 \% \mathrm{~A}$ and $60 \% \mathrm{~B}$; at $5-50 \mathrm{~min}$ with the ratio of $40 \%-60 \% \mathrm{~A}$ and $60 \%-40 \% \mathrm{~B}$; at $50-65$ min with the ratio of $60 \%-40 \% \mathrm{~A}$ and $40 \%-60 \% \mathrm{~B}$. The UV wavelength, flow rate, and injection volume were set at $254 \mathrm{~nm}, 0.8 \mathrm{~mL} / \mathrm{min}$, and $10 \mu \mathrm{L}$, respectively.

\subsection{Statistics Analysis}

Values are expressed as means \pm SD and analyzed using one way ANOVA followed by Fisher's protected least significant difference test for comparisons of group means, when the $\mathrm{F}$ value was significant $(\mathrm{P}<0.05)$. All statistical analyses were performed using SPSS for Windows, version 10 (SPSS, Inc.); a P value < 0.05 is considered statistically significant.

\section{Results and Discussion}

\subsection{Analgesic Effects of HME in Hot-Plate Test and in AA-Induced Writhing Test}

Hot-plate test was used to evaluate the central analgesic effects [14]. All groups exhibited similar latency to lick paws before administration (Table 1). HME administration significantly and dose-dependently increased the latency to lick paws before and after administration, especially at high dose of HME 
Table 1. Analgesic effects of HME in hot-plate test and acetic acid-induced writhing test.

\begin{tabular}{|c|c|c|c|c|}
\hline \multirow{3}{*}{ Groups } & \multicolumn{3}{|c|}{ Hot-plate test } & AA-induced writhing test \\
\hline & Before Administration & After Administration & Difference & \multirow{2}{*}{ Number of writhing within $10 \mathrm{~min}$} \\
\hline & \multicolumn{3}{|c|}{ The latency to licking paws (sec) } & \\
\hline Control & $11.8 \pm 4.7$ & $12.3 \pm 4.5$ & $0.5 \pm 0.6^{\mathrm{a}}$ & $42.5 \pm 4.3^{\mathrm{a}}$ \\
\hline Aspirin & $11.3 \pm 1.2$ & $19.0 \pm 2.8$ & $7.7 \pm 3.3^{\mathrm{c}}$ & $17.3 \pm 4.1^{\mathrm{b}}$ \\
\hline HME 77 & $11.5 \pm 3.9$ & $12.8 \pm 3.5$ & $1.3 \pm 0.8^{\mathrm{ab}}$ & $35.0 \pm 2.4^{\mathrm{cf}}$ \\
\hline HME 154 & $12.0 \pm 3.9$ & $15.7 \pm 4.5$ & $3.7 \pm 1.5^{\mathrm{ab}}$ & $31.0 \pm 3.6^{\text {cde }}$ \\
\hline HME 308 & $11.2 \pm 2.7$ & $21.8 \pm 6.2$ & $10.7 \pm 4.4^{\mathrm{c}}$ & $27.2 \pm 6.0^{\mathrm{e}}$ \\
\hline IMP 0.6 & $10.3 \pm 1.2$ & $14.0 \pm 2.8$ & $3.7 \pm 2.2^{\mathrm{ab}}$ & $39.7 \pm 3.6^{\mathrm{af}}$ \\
\hline IMP 1.2 & $10.0 \pm 2.5$ & $14.5 \pm 2.9$ & $4.5 \pm 1.2^{\mathrm{b}}$ & $35.8 \pm 2.6^{\mathrm{cf}}$ \\
\hline OST 2.2 & $9.8 \pm 1.6$ & $14.0 \pm 2.6$ & $4.2 \pm 2.5^{\mathrm{b}}$ & $33.5 \pm 6.4^{\mathrm{cd}}$ \\
\hline OST 4.4 & $10.3 \pm 3.2$ & $18.8 \pm 5.2$ & $8.2 \pm 3.6^{\mathrm{c}}$ & $28.3 \pm 4.1^{\mathrm{de}}$ \\
\hline
\end{tabular}

Values are expressed as mean $\pm \mathrm{SD}$; mean in each column not sharing a letter differ statistically, $P<0.05$. Abbreviation: HME, herbal mixture extract; IMP, imperatorin; OST, osthol.

with increasing from $0.5 \mathrm{~s}$ to $10.7 \mathrm{~s}$, as compared to control group (Table 1), indicating that HME has central analgesic potential. Aspirin used as positive control in all animal models of this study and was shown to possess analgesic effect in hot-plate test in mice [15]. Our finding also revealed that aspirin exhibited analgesic effects in hot-plate test (Table 1), indicating that this assay was valid. Results also revealed that OST and IMP significantly and dose-dependently increased the latency to lick paws before and after administration, especially at high dose (Table 1), suggesting that OST and IMP may partially involve in the analgesic effect of HME.

The writhing test induced by AA via i.p. injection is an experimental model used for determining the central and peripheral analgesic activity of drugs [16]. In addition, a good relationship exists between the potencies of analgesics in writhing test and their clinical potencies [17]. AA was shown to increase levels of pain mediators, such as prostaglandin $\mathrm{E} 2\left(\mathrm{PGE}_{2}\right), \mathrm{PGF}_{2} \alpha$, serotonin, and histamine, in peritoneal fluids [18] followed by induction of writhing response, including contraction of abdominal muscles, extension of the forelimbs, and elongation of the body [19]. Herein, we found that HME administration significantly and dose-dependently decreased AA-induced writhing counts, with an inhibition of $36 \%$, as compared to control group (Table 1). A comparison done on AA-induced pain showed that aspirin had $59 \%$ inhibition, as compared to control group (Table 1). The mechanism of aspirin is to decrease the formation of pain mediators in the peripheral tissues [20]. Results also revealed that only OST administration significantly decreased AA-induced writhing counts in a dose-dependent manner (Table 1), indicating that OST may play more important role in analgesic effects than that of IMP. Further studies are needed to elucidate the exact mechanism underlying such action of HME. 


\subsection{Anti-Inflammatory Effects of HME in AA-Induced Vascular Permeability Test}

AA was shown to increase inflammatory mediators, including PGE2, histamine, and serotonin, in peritoneal fluids followed by induction of vascular permeability [21]. AA-induced vascular permeability is one of the acute inflammatory models [14]. We found that AA increased vascular permeability, as evidenced by dramatically increased the value of OD590 $\mathrm{nm}$ in peritoneal fluids, as compared to control group (Table 2). Experimental data revealed that HME administration significantly and dose-dependently decreased AA-induced vascular permeability, with inhibition of $45 \%$, as compared to AA group (Table 2). Similar finding was observed in aspirin administration group (Table 2). However, only OST significantly reduced AA-induced vascular permeability in a dose-dependent manner (Table 2), indicating that OST may partially involve in anti-inflammation of HME.

\subsection{Dose Translation from Human to Mice and the Content of OST and IMP in HME}

We stipulated that the recommended dietary allowance (RDA) of HME in humans is $1.5 \mathrm{~g}$ per day on the basis of HME as a commercial dietary supplement in Taiwan. In all mice models, a formula available for converting human equivalent dose to animal dose in $\mathrm{mg} / \mathrm{kg}$, i.e., multiply the human dose in $\mathrm{mg} / \mathrm{kg}$ per day by 12.3 [22]. The high dose $(308 \mathrm{mg} / \mathrm{kg})$ of HME in mice was obtained by the equation: $25 \mathrm{mg} / \mathrm{kg}(1.5 \mathrm{~g}$ per $60 \mathrm{~kg}$ person $) \times 12.3$. The medium $(154 \mathrm{mg} / \mathrm{kg})$ and low dose $(77 \mathrm{mg} / \mathrm{kg})$ of HME were selected based on a half fold and one-quarter fold from the high dose of HME, respectively.

It should be noted that just one batch-specific formulation of HME was used to determine pharmacological effects in mice. We used OST and IMP as bioactive compounds to ensure the quality of manufactured HME and as in HME. The content of OST and IMP in HME was $3.57 \pm 0.10 \mathrm{mg} / \mathrm{g}$ and $1.20 \pm 0.02$ $\mathrm{mg} / \mathrm{g}$, respectively, from three independent batches (Figure 1). In humans, the consumption of IMP and OST are about $1.5 \mathrm{mg}$ and $5.4 \mathrm{mg}$ per day, respectively $(0.025 \mathrm{mg} / \mathrm{kg}$ for IMP and $0.09 \mathrm{mg} / \mathrm{kg}$ for OST). By calculation [22], the doses of IMP and OST in mice are equal to $0.3 \mathrm{mg} / \mathrm{kg}$ and $1.1 \mathrm{mg} / \mathrm{kg}$, respectively. The low and high dose of IMP and OST were selected based on two- and four-fold from the calculated dose, respectively.

Most of medicinal effects of Fructus Cnidii are considered to attribute to coumarins, such as OST and IMP [23] [24]. OST exhibited broad spectrum of pharmacological activities [25], including anti-oxidant, anti-inflammation, neuroprotective effects, osteogenic effects, immunomodulation, anticancer effects, hepatoprotective effects, cardiovascular protective effects, and antimicrobial activities. IMP was shown to possess several biological functions [26], including anti-inflammatory, antibacterial, antifungal, antiviral, anticancer, and anticonvulsant. Herein, we found that OST administration at two- and four-fold of RDA levels exhibited potent inhibitory effects, indicating that OST may partially involve in protective actions of HME. 
Table 2. Anti-inflammatory effects of HME in acetic acid-induced peritoneal permeability test.

\begin{tabular}{cc}
\hline Groups & Value of OD $_{590 \mathrm{~nm}}$ \\
\hline Control & $0.03 \pm 0.00^{\mathrm{a}}$ \\
AA & $2.96 \pm 0.11^{\mathrm{b}}$ \\
AA + Aspirin & $2.12 \pm 0.45^{\text {cd }}$ \\
AA + HME 77 & $2.19 \pm 0.48^{\mathrm{c}}$ \\
AA + HME 154 & $1.94 \pm 0.42^{\text {cd }}$ \\
AA + HME 308 & $1.62 \pm 0.33^{\mathrm{d}}$ \\
AA + IMP 0.6 & $2.87 \pm 0.16^{\mathrm{b}}$ \\
AA + IMP 1.2 & $3.06 \pm 0.03^{\mathrm{b}}$ \\
AA + OST 2.2 & $2.06 \pm 0.26^{\mathrm{cd}}$ \\
AA + OST 4.4 & $1.89 \pm 0.20^{\text {cd }}$ \\
\hline
\end{tabular}

Values are expressed as mean $\pm \mathrm{SD}$; mean in each column not sharing a letter differ statistically, $\mathrm{P}<0.05$. Abbreviation: AA, acetic acid; HME, herbal mixture extract; IMP, imperatorin; OST, osthol.

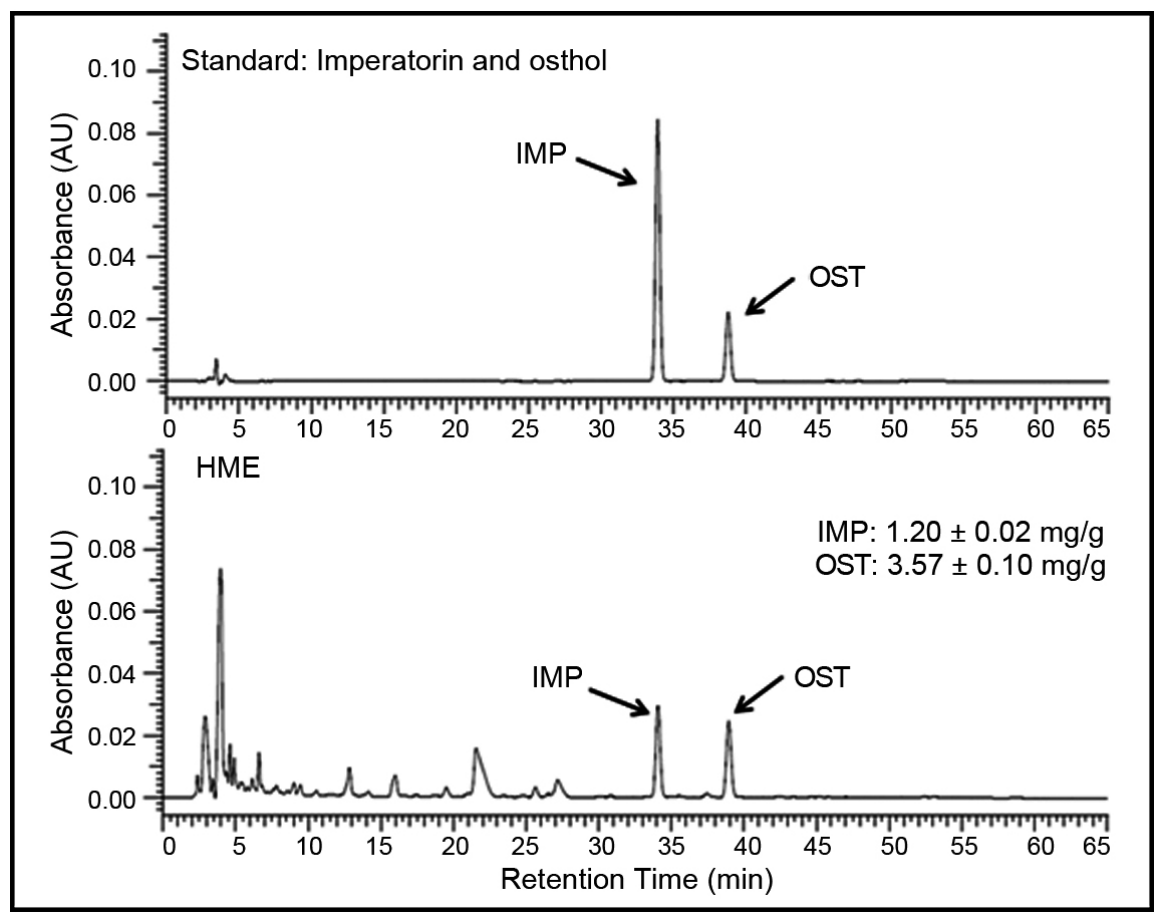

Figure 1. HPLC chromatogram of osthol (OST) and imperatorin (IMP) in herbal mixture extracts (HME). The upper panel is the HPLC chromatogram of standard OST and IMP. The lower panel is the HPLC chromatogram of OST and IMP in HME. The content of OST and IMP is expressed as mean \pm SD from three batches.

\section{Acknowledgements}

This research was supported by E10100034-204 from the Small Business Innovation Research (SBIR), Ministry of Economic Affairs, Taiwan. 


\section{References}

[1] Williamson, E.M. (2001) Synergy and Other Interactions in Phytomedicines. Phytomedicine, 8, 401-409. https://doi.org/10.1078/0944-7113-00060

[2] Yang, Y., Zhang, Z., Li, S., Ye, X., Li, X. and He, K. (2014) Synergy Effects of Herb Extracts: Pharmacokinetics and Pharmacodynamic Basis. Fitoterapia, 92, 133-147. https://doi.org/10.1016/j.fitote.2013.10.010

[3] Son, G.S. (2006) Effect of Soybean Intake on Bone Mineral Density and Bone Turnover Markers in Postmenopausal Women. Taehan Kanho Hakhoe Chi, 36, 933-941 [Article in Korean]. https://doi.org/10.4040/jkan.2006.36.6.933

[4] Kim, H.J., Xu, L., Chang, K.C., Shin, S.C., Chung, J.I., Kang, D., Kim, S.H., Hur, J.A., Choi, T.H., Kim, S. and Choi, J. (2012) Anti-Inflammatory Effects of Anthocyanins from Black Soybean Seed Coat on the Keratinocytes and Ischemia-Reperfusion Injury in Rat Skin Flaps. Microsurgery, 32, 563-570. https://doi.org/10.1002/micr.22019

[5] Messina, M.J., Persky, V., Setchell, K.D. and Barnes, S. (1994) Soy Intake and Cancer Risk: A Review of the in vitro and in vivo Data. Nutrition and Cancer, 21, 113-131. https://doi.org/10.1080/01635589409514310

[6] García-Lafuente, A., Guillamón, E., Villares, A., Rostagno, M.A. and Martínez, J.A. (2009) Flavonoids as Anti-Inflammatory Agents: Implications in Cancer and Cardiovascular Disease. Inflammation Research, 58, 537-552. https://doi.org/10.1007/s00011-009-0037-3

[7] Zhang, F.Q., Peng, X.L., Qu, H.Q., Chang, Y.Q. and Wei, F.H. (2007) Study on Effects of Soybean Plant Extract on Anti-Inflammatory and Analgesic. Food Science, 11, 533-536 [Article in Chinese].

[8] He, J., Feng, M.L., Liu, X., Jia, L.L., Wu, Y.P. and Niu, Y.Y. (2007) The Sedative and Hypnotic Action of Fructus Cnidii Extracts. Shanxi Journal of Traditional Chinese Medicine, 5, 61-62 [Article in Chinese].

[9] Wu, H.X., Wang, Y.M., Xu, H., Wei, M., He, Q.L., Li, M.N., Sun, L.B. and Cao, M.H. (2017) Osthole, A Coumadin Analog from Cnidium monnieri (L.) Cusson, Ameliorates Nucleus Pulposus-Induced Radicular Inflammatory Pain by Inhibiting the Activation of Extracellular Signal-Regulated Kinase in Rats. Pharmacology, 100, 74-82. https://doi.org/10.1159/000475599

[10] Chao, X., Zhou, X., Zheng, G., Dong, C., Zhang, W., Song, X. and Jin, T. (2014) Osthole Induces G2/M Cell Cycle Arrest and Apoptosis in Human Hepatocellular Carcinoma HepG2 Cells. Pharmaceutical Biology, 52, 544-550. https://doi.org/10.3109/13880209.2013.850517

[11] Li, F., Gong, Q., Wang, L. and Shi, J. (2012) Osthole Attenuates Focal Inflammatory Reaction Following Permanent Middle Cerebral Artery Occlusion in Rats. Biological and Pharmaceutical Bulletin, 35, 1686-1690. https://doi.org/10.1248/bpb.b12-00133

[12] Wang, H.L., Li, Y.X., Niu, Y.T., Zheng, J., Wu, J., Shi, G.J., Ma, L., Niu, Y., Sun, T. and Yu, J.Q. (2015) Observing Anti-Inflammatory and Anti-Nociceptive Activities of Glycyrrhizin through Regulating COX-2 and Pro-Inflammatory Cytokines Expressions In Mice. Inflammation, 38, 2269-2278. https://doi.org/10.1007/s10753-015-0212-3

[13] Wan, X.Y., Luo, M., Li, X.D. and He, P. (2009) Hepatoprotective and Anti-Hepatocarcinogenic Effects of Glycyrrhizin and Matrine. Chemico-Biological Interactions, 181, 15-19. https://doi.org/10.1016/j.cbi.2009.04.013 
[14] Zhang, L., Hu, J.J., Lin, J.W., Fang, W.S. and Du, G.H. (2009) Anti-Inflammatory and Analgesic Effects of Ethanol and Aqueous Extracts of Pterocephalus Hookeri (C.B. Clarke) Hoeck. Journal of Ethnopharmacology, 123, 510-514. https://doi.org/10.1016/j.jep.2009.01.039

[15] Shakir, R., Muhi-Eldeen, Z.A., Matalka, K.Z. and Qinna, N.A. (2012) Analgesic and Toxicity Studies of Aminoacetylenic isoindoline-1,3-dione Derivatives. ISRN Pharmacology, 2012, Article ID: 657472. https://doi.org/10.5402/2012/657472

[16] Su, Y.F., Yang, Y.C., Hsu, H.K., Hwang, S.L., Lee, K.S., Lieu, A.S., Chan, T.F. and Lin, C.L. (2015) Toona sinensis Leaf Extract Has Antinociceptive Effect Comparable with Non-Steroidal Anti-Inflammatory Agents in Mouse Writhing Test. BMC Complementary and Alternative Medicine, 15, 70.

https://doi.org/10.1186/s12906-015-0599-2

[17] Zhou, H., Wong, Y.F., Cai, X., Liu, Z.Q., Jiang, Z.H., Bian, Z.X., Xu, H.X. and Liu, L. (2006) Suppressive Effects of JCICM-6, the Extract of an Anti-Arthritic Herbal Formula, on the Experimental Inflammatory and Nociceptive Models in Rodents. Biological and Pharmaceutical Bulletin, 29, 253-260. https://doi.org/10.1248/bpb.29.253

[18] Deraedt, R., Jouquey, S., Delevallée, F. and Flahaut, M. (1980) Release of Prostaglandins $\mathrm{E}$ and $\mathrm{F}$ in an Algogenic Reaction and Its Inhibition. European Journal of Pharmacology, 61, 17-24. https://doi.org/10.1016/0014-2999(80)90377-5

[19] Hernández-Pérez, M. and Rabanal, R.M. (2002) Evaluation of the Antinflammatory and Analgesic Activity of Sideritis canariensis var. Pannosa in Mice. Journal of Ethnopharmacology, 81, 43-47. https://doi.org/10.1016/S0378-8741(02)00033-8

[20] Bhutia, Y.D., Vijayaraghavan, R. and Pathak, U. (2010) Analgesic and Anti-Inflammatory Activity of Amifostine, DRDE-07, and Their Analogs, in Mice. Indian Journal of Pharmacology, 42, 17-20. https://doi.org/10.4103/0253-7613.62401

[21] Choi, J.H., Jung, B.H., Kang, O.H., Choi, H.J., Park, P.S., Cho, S.H., Kim, Y.C., Sohn, D.H., Park, H., Lee, J.H. and Kwon, D.Y. (2006) The Anti-Inflammatory and Anti-Nociceptive Effects of Ethyl Acetate Fraction of Cynanchi Paniculati Radix. Biological and Pharmaceutical Bulletin, 29, 971-975. https://doi.org/10.1248/bpb.29.971

[22] Reagan-Shaw, S., Nihal, M. and Ahmad, N. (2008) Dose Translation from Animal to Human Studies Revisited. FASEB Journal, 22, 659-661. https://doi.org/10.1096/fj.07-9574LSF

[23] You, L., Feng, S., An, R. and Wang, X. (2009) Osthole: A Promising Lead Compound for Drug Discovery from a Traditional Chinese Medicine (TCM). Natural Product Communications, 4, 297-302.

[24] Li, Y.M., Jia, M., Li, H.Q., Zhang, N.D., Wen, X., Rahman, K., Zhang, Q.Y. and Qin, L.P. (2015) Cnidium monnieri: A Review of Traditional Uses, Phytochemical and Ethnopharmacological Properties. The American Journal of Chinese Medicine, 43, 835-877. https://doi.org/10.1142/S0192415X15500500

[25] Zhang, Z.R., Leung, W.N., Cheung, H.Y. and Chan, C.W. (2015) Osthole: A Review on Its Bioactivities, Pharmacological Properties, and Potential as Alternative Medicine. Evidence-Based Complementary and Alternative Medicine, 2015, Article ID: 919616. https://doi.org/10.1155/2015/919616

[26] Venugopala, K.N., Rashmi, V. and Odhav, B. (2013) Review on Natural Coumarin Lead Compounds for Their Pharmacological Activity. BioMed Research International, 2013, Article ID: 963248. https://doi.org/10.1155/2013/963248 